double as compared to farm A. From a financial point of view, the cash flow of farm B is positive within three years whereas on farm $A$ it is negative throughout the period. At the end of the period, net results have increased almost fourfold on farm B as compared to farm $A$.

These differences indicate that productivity should be improved before considering a growth of the production unit. In the present case, farm A would obtain better results by reaching the level of performances observed in the group of the best farms rather than by doubling the size of the breeding unit.

\title{
Inflation and pig production
}

\author{
E. RENOUX
}

C.P.S.E., Canappeville, 27400 Lonviers (France)

The present study deals with the incidence of the last 5 years of inflation on pig production cost-price.

The cyclic effect of inflation on animal feeding increases the advantage of home produced feeds. This advantage can be added to the constantly over-estimated amortizations and financial costs for the benefit of farmers established since many years as compared with young pig producers whose qualifications can hardly compensate for the harmful incidence of inflation.

To restore the balance within 5 years, it would be necessary to improve the productivity of the sows (number of commercialized piglets /sow/year) and the feed conversion ratio by 4 standard deviations as compared with present means obtained in the technico-economical management of pigs.

\section{Financing of a pig production unit. Theoretical approach to problems concerning investment costs, rates of interest and of self-financing (Case of a rearing-fattening unit with a herd of 84 sows)}

\author{
J.-M. ANGOTTI \\ I.T.P., I 49 , ne de Bevcy, 75579 Paris Cedex 12
}

The author studies the relationships between rates of interest on loan, self-financing, redemption capacity and rates of return for a project with several productivity levels through simulations calculated for a herd of 84 sows.

Through this model, maximum rates (allowing redemption of loan) were defined for different investment, productivity and self-financing levels.

It is established that for average-performances, the rate of self-financing should vary between $o$ and 33 per cent according to the average rate of interest and the value of investments. However, for good performance, the need for self-financing is always null for the usual rates of interest.

In order to obtain a significant prevision of the redemption capacity, it is necessary to consider all investigated parameters (value of investments, technicity level, rate of interest on loan, self-financing). However, the anticipated productivity seems to be the determining factor for obtaining the required redemption capacity and economic efficiency of the project. 